\title{
Phase and electron microscopic observations of osmotically induced wrinkling and the role of endocytotic vesicles in the plasmolysis of the Gram-negative cell wall
}

\author{
Heinz Schwarz and Arthur L. Koch† \\ Author for correspondence: Arthur L. Koch. Tel: +1 812855 5036. Fax: +1 8128556705. \\ e-mail: Koch@Indiana.edu
}

Max-Planck-Institut für Entwicklungsbiologie, Spemannstrasse 35, D-72076 Tubingen, Germany
When a Gram-negative bacterium is challenged with a sufficient concentration of a non-penetrating solute such as sucrose, water is sucked out of the cell. Plasmolysis spaces may form if the cell's cytoplasmic membrane (CM) separates from the murein wall (M) and the outer membrane (OM). However, we suggest that first wrinkling of the wall envelope, forced by dehydration of the cytoplasm, occurs. The cryofixation, freeze-substitution electron microscope studies used here are much too slow to study the kinetics of shrinkage, wrinkling and plasmolysis. However, they are consistent with faster phase microscope studies and previous stopflow experiments. For the electron microscopy studies reported here, only sucrose was used as the osmotic agent and under conditions that do not cause extreme plasmolysis. Plasmolysis spaces were associated with the formation of small membrane-bound vesicles in the nearby cytoplasm. Such vesicles formed by osmotic challenge are called 'endocytotic' in plant cell systems. They had been recorded in earlier plasmolysis studies in bacteria, but not interpreted as a concomitant part of plasmolysis space formation in certain locations of the cell. We suggest that the endocytotic vesicles form because the phospholipid membranes are capable of very little contraction so extra membrane must be disposed of when plasmolysis spaces form. In the case of plasmolysis spaces forming at poles and constriction sites, for geometric reasons the surface area of the $\mathrm{CM}$ may be conserved without disposition of excess membrane. We suggest that it is this biophysical property of lipid membranes that leads to the frequent formation of plasmolysis spaces at a pole and at the site of future division. We also observed a novel structure, this is only seen under mild osmotic up-shock, and consists of very thin, straight, uniform and long plasmolysis spaces which were called 'Iamellar spaces'; these commonly formed inside the sidewalls and were usually associated with the formation of endocytotic vesicles. Since lipoprotein links the $M$ to the $O M$ layers and thus could affect plasmolysis, we examined both wild-type and deficient strains. Some effects were observed, but they were minimal. The volume of the periplasmic space of growing unshocked cells was determined to be about $7 \%$.

Keywords: endocytotic vesicles, plasmolysis, wrinkling cell wall, periplasmic space, Escherichia coli $\lceil$ Present address: Biology Department, Indiana University, Bloomington, IN 47405-6801, USA.

Abbreviations: CM, cytoplasmic membrane; $\mathrm{EM}$, electron microscope/ microscopy; $M$, murein wall; OM, outer membrane.

\section{INTRODUCTION}

The study of bacterial plasmolysis is nearly a century old (Fischer, 1891), although much younger than plasmolysis studies in animals (see Heilbrunn, 1952) and plants (de 
Vries, 1877). The phenomenon is different in bacteria because of the presence of a strong, stretchable and flexible sacculus which surrounds, contains and restrains the cytoplasm, and because bacteria are not part of a tissue of cells. Even the Gram-positive cell wall is thin and flexible compared to the walls of plant cells. In plants, an increase in osmotic pressure causes the cytoplasmic membrane to shrink away from the very thick rigid cellulosic wall (see Nobel, 1983). In this paper, we suggest that the outer membrane (OM) of the Gram-negative organism, the murein wall $(\mathrm{M})$, and the cytoplasmic membrane (CM) of Escherichia coli contract together to produce a wrinkled composite wall containing all layers. We argue that this wrinkled composite material may, in certain cases, then split to dissociate the $\mathrm{CM}$ from the $\mathrm{M}-\mathrm{OM}$ layers, allowing partial straightening and relaxation of the outer two layers and permitting them to reextend, thereby producing a plasmolysis space. A number of secondary processes occur which allows the $\mathrm{CM}$ to straighten. However, the dominant process during the relatively mild up-shock used throughout most of this study is the invagination and pinching off of $\mathrm{CM}$ to form 'endocytotic' vesicles; these are usually quite small and appear to contain periplasm. We use the 'endocytotic' designation because of its previous use to describe similar vesicles produced in plant protoplasts by osmotic challenge (see Kell \& Glaser, 1993). The development of membrane-bound endocytotic vesicles is usually considered as a process in animal cells, but it has now been seen in plant cells that had had their walls removed (Kell \& Glaser, 1993), and, in the present report, in bacterial cells as well. The formation of vesicles causes the area of the $\mathrm{CM}$ remaining on the surface of the cytoplasm to be reduced. The result is that the plasmolysis space is bounded by a relaxed and straightened or gently curved $\mathrm{CM}$ and an almost unwrinkled $\mathrm{M}-\mathrm{OM}$ layer.

We will use the term plasmolysis 'space' (Olijhoek et al., 1982) instead of 'vacuole' (Cota-Robles, 1963) or 'bay' (Cook et al., 1987, 1989; Rothfield et al., 1991; Cook \& Rothfield 1994a, b; MacAlister et al., 1983, 1987) because the use of the term 'space' for a volume of the biological fluid of an organism that can equilibrate with a test probe has historical precedence (Heilbrunn, 1952). The present usage of 'plasmolysis space' is also consistent with the extension of the concept of the 'periplasmic space' as an enlarged 'space' resulting from hyperosmotic shock.

Three new views are presented here: first, that the formation of plasmolysis spaces is a relaxation process subsequent to the rapid wrinkling after osmotic up-shock and occurs when the $\mathrm{CM}$ is able to separate from the remainder of the wrinkled wall; second, that usually less bilayer is needed for the inner surface of the plasmolysis space and this requires disposition of the excess in some way, such as vesicle formation; third, plasmolysis spaces are more likely to develop in locations of special geometry, such as the poles and the developing constriction sites where there is no necessity for excess membrane disposal.

\section{METHODS}

Strains. Before the studies were initiated it was envisaged that the presence of lipoprotein would greatly influence the results. Generally only minor effects were found, but the use of two pairs of independent strains serves as a replication of the experimental results. Two strains were obtained from Professor Isao Shibuya at Saitama University, Urawa, Japan, Ch104Tc and Ch105Tc (Asaai et al., 1989): Ch104Tc is $\mathrm{F}^{-} \Delta(l p p$-aro) galK35 his-68 malA1 mtl-2 gyr $A$ pyrD34 rpsL118 thy $A$ trp-45 xyl-7 uvrC279:: $\operatorname{Tn} 10 ; \mathrm{CH} 105 \mathrm{Tc}$ is the same with the deletion $\Delta(l p p$-aro $)$, replaced with the wild-type DNA. These organisms were used for the data given in Table 1 . Additionally we have used JA221, which is $l p p h s d M^{+}$bsdR trpE5 leuB6 lac $Y$ lac $Z$ rel $A 1 / \mathrm{F}^{\prime}$ lac ${ }^{\mathrm{q}}$ pro $A^{+}$proB $B^{+}$, and a plasmid-bearing form containing a derivative of $\mathrm{pKEN} 115$. This, designated $\mathrm{pR} 78$, has the lipoprotein gene modified so that the terminal lysine of the lipoprotein was converted to an arginine; it was a gift of Henry Wu (Zhang \& Wu, 1992; Zhang et al., 1992). The genetics of this locus goes back through a series of papers (Asaai et al., 1989; Braun \& Wu, 1994; Hiemstra, 1987; Hiemstra et al., 1987; Hirota et al., 1977; Nakamura et al., 1982; Sonntag et al., 1978; Suzuki et al., 1978). This arginine replacement prevents the lipoprotein from being linked to diaminopimelic acid residues of the murein wall. From this we derived a revertant that is wild-type with respect to its sensitivity to SDS, presumably replacing the arginine by lysine as in the wild-type; we chose this way of getting a wild-type lipoprotein to insure isogenicity. This method works because of the strong selective pressure provided by growth in SDS and because the chromosomal inactive copy of the $l p p$ gene is not revertible under these conditions.

Growth conditions. Large cells were needed for critical observations in the phase microscope, therefore all media were based on rich LB broth (Miller, 1972). Although the bacteria can grow normally without any additional $\mathrm{NaCl}$, the medium contained $10 \mathrm{~g}$ Bacto tryptone, $5 \mathrm{~g}$ yeast extract $\mathrm{l}^{-1}$ plus $10 \mathrm{~g}$ $\mathrm{NaCl}$ as in the version cited in Miller (1972) for the EM studies. In some experiments, the $\mathrm{NaCl}$ was omitted in order to induce the formation of membrane-derived oligosaccharides and control the osmotic pressure difference between the periplasm and the medium more accurately. To this we added all the requirements for JA221 and Ch104 Tc and Ch105 Tc $(50 \mu \mathrm{g}$ $\mathrm{ml}^{-1}$ each of His, Thy, Trp, Leu, and Pro) plus $10 \mu \mathrm{g}$ tetracycline $\mathrm{ml}^{-1}$; we designated this medium $\mathrm{LB}^{+}$or $\mathrm{LB}^{ \pm}$, for with and without added $\mathrm{NaCl}$. Medium was supplemented with $1 \%$ $(\mathrm{w} / \mathrm{v})$ lactose when JA221/ $\mathrm{F}^{\prime}$ lac $\mathrm{I}^{\mathrm{q}}$ was to be induced to cause the formation of lipoprotein from the pKEN115 or its derivatives. All cultures were grown at $37^{\circ} \mathrm{C}$ and aerated by shaking.

Electron microscopy (EM). The actively growing control and osmotically challenged cells were immediately pelleted with an Eppendorf $5415 \mathrm{C}$ centrifuge at 8000 r.p.m. for $2 \mathrm{~min}$. While we prepared the samples as rapidly as possible, there were still several minutes during which changes in the wall shape and adaptations to the osmotic challenge, centrifugation and potential anaerobiosis could have occurred before the cells were frozen. To try to study the kinetics, the centrifugation was omitted and only one grid was made from each osmotic upshocked culture. The cell suspensions were promptly transferred to glow-discharged 200 mesh copper grids of $10 \mu \mathrm{m}$ thickness and sandwiched been two copper platelets. The samples were cryofixed with liquid propane to below $-180^{\circ} \mathrm{C}$ using a jet freeze device (Balzers JDF 030). Frozen samples were freezesubstituted in water-free acetone containing $1 \%(\mathrm{w} / \mathrm{v})$ osmium tetroxide for $12 \mathrm{~h}$ at $-90^{\circ} \mathrm{C}, 5 \mathrm{~h}$ at $-60^{\circ} \mathrm{C}$ and $3 \mathrm{~h}$ at $-30^{\circ} \mathrm{C}$ 
in a Balzers FSU 010. After removing the substitution medium the cells were washed twice with acetone and impregnated with Epon/acetone at $-30^{\circ} \mathrm{C}$. The samples were infiltrated with Epon at room temperature and finally polymerized at $60^{\circ} \mathrm{C}$ for $2 \mathrm{~d}$ (for details see Schwarz et al., 1993). Ultrathin sections were stained with uranyl acetate and lead citrate and viewed in a Philips CM10 electron microscope at $60 \mathrm{kV}$ using a $30 \mu$ objective aperture. All micrographs were taken in the eccentric plane of the objective lens. For optimal imaging of the membrane and murein layers of the cell wall the sections were tilted using a goniometer.

Plasmolysis studies with the phase microscope. The most usual procedure was to remove a few $\mathrm{ml}$ of an early exponentialphase culture from the shaker and use this immediately; however, sometimes samples were left on the bench for as much as $2 \mathrm{~h}$ for control purposes. Up to three components were pipetted as separate droplets onto a microscope slide to a total volume of $20 \mu \mathrm{l}$. All reagents usually contained $20 \mathrm{mM} \mathrm{NaN}_{3}$ so that the final concentration was at least $10 \mathrm{mM}$ for the data given here; this was done to prevent the cells from adapting to the osmotic change, but was probably not necessary, particularly, for immediate observation. These droplets were then mixed with a \#0 cover slide that was then placed on top of the mixture, and the slide viewed under oil with a $100 \times$ phase 3 objective. Most observations were made within $30 \mathrm{~s}$ and sometimes in only $15 \mathrm{~s}$ from the time of osmotic up-shock. The critical conclusions were drawn from cultures taken from exponential growth, up-shocked, and free-floating cells examined within $15-20 \mathrm{~s}$.

\section{RESULTS}

\section{EM appearance of exponentially growing cells}

Longitudinal and cross-sections of $l p p^{+}$and $l p p$ bacteria are shown in Figs 1 and 2. [In these figures and in Figs 3-7, the (a) shows the wild-type cell and (b) shows the lipoprotein-deficient cell.] The two strains do not differ in appearance when unchallenged. Notice the smooth and closely apposed sandwich of the three layers. Exceptional, very rare morphologies are shown in Fig. 3. These unusual cells are shown to delineate the range of appearance of cells in the same population. Fig. 3(a) shows a laminar plasmolysis space: in unchallenged cells these are very rare ( $<1$ in 2000 cells) but very common in osmotically up-shocked cells. Fig. 3(b) shows an equally rare cell with somewhat wrinkled outer surface: these too are very rare. However, when cells actively growing in the LB broth are osmotically challenged to a final concentration of $16 \%(\mathrm{w} / \mathrm{v})$ sucrose, most cells have, at least, some wrinkled, non-plasmolysed, wall regions usually more wrinkled than shown in Fig. 3(b) (see Figs 4-6). Under more severe up-shocks, still other morphologies were seen (see Koch, 1995; Woldringh, 1994), but none of these were seen after exhaustive examination of cells that had not been osmotically challenged. Also, as contrasted with the osmotically challenged cells, endocytotic vesicles were never observed. Finally, polar plasmolysis spaces were never seen.

\section{Appearance of osmotically challenged cells}

All the EM studies in this paper concern cells grown in LB medium which contains $10 \mathrm{~g} \mathrm{NaCl}^{-1}$ so that they had no membrane-derived oligosaccharides (Kennedy, 1982). They were osmotically up-shocked from the actively growing state by being brought to $16 \%(\mathrm{w} / \mathrm{v})$ sucrose. This is a relatively mild osmotic challenge, largely because the cells were grown in this high salt medium (see Koch, 1995). Longitudinal- and cross-sections of the shocked bacteria are shown in Figs 4 and 5. Note the appearance of several types of plasmolysis spaces and particularly the development of membrane-bound endocytotic vesicles which are generally very near the $\mathrm{CM}$. It will be concluded (see Discussion) that the vesicle formation allows the bilayer material covering the cytoplasm to be disposed of and thus the $\mathrm{CM}$ becomes able to straighten out. There are alternative ways for the non-compressible lipid membrane to smoothly cover the cytoplasm (Fig. 6): these are the formation of large endocytotic vesicles and of exocytotic protrusions/vesicles. There are other types of responses when more severe osmotic challenges are employed: rough irregular $\mathrm{CM}$ surrounding a very shrunken cytoplasm; disk-shaped collapsed cytoplasm; and tubular outpouching of the cytoplasmic region. These have been studied in the earlier work of many others and are collectively discussed by Koch (1995) and experimentally studied by Schwarz \& Koch (unpublished).

The alternative morphology to plasmolysis space formation is the maintenance of a wrinkled, shrunken cell wall as shown in Fig. 7. These cells were taken from the same cultures as those in Figs 3 and 4. Both wrinkled and plasmolysed cells were equally abundant in both the wild-type (a) and in the lipoprotein-deficient (b) cultures. Subjectively, it was concluded that plasmolysis was slightly more likely in the wild-type, consistent with the data obtained with the phase microscopic studies (see below) which identified differences between the strains dependent on the degree of osmotic up-shock. Moreover, Fig. 8(a) shows an intermediate, but common, case where the same cell had both wrinkled and plasmolysed regions. Fig. 8(a) additionally shows a rare aspect, so far only seen once and in a lipoprotein-deficient strain: this is the $\mathbf{M}$ layer actually separated from the $\mathrm{CM}$ as well as the $\mathrm{OM}$ layers. Fig. 8(b) shows the full separation of the CMcovered cytoplasm on both sides of a developing constriction; it is unlikely that cytoplasm on the two halves of this cell is actually connected. We conclude this because the section appears to be axial and the curvature of the CMs does not suggest such a connection. Fig. 8(c) shows a rare periplasmic space extending through the cell (a 'complete' space) in a region in which there is little likelihood of it being a site for division. Note the frequent occurrence of the laminar spaces and the endocytotic vesicles in Figs 4, 5, 6 and 8. We also occasionally observed complete spaces at sites where presumptively division will take place, but where the constriction was not as well developed as in Fig. 8(b). These cases suggests that the bacteria were already physiologically two cells before actual division as demonstrated by Clark (1968).

\section{Dimensions of cell walls and cell widths}

Table 1 lists the average thickness of the $\mathrm{CM}$ and the $\mathrm{M}-\mathrm{OM}$ couple measured in regions of plasmolysis. It also 

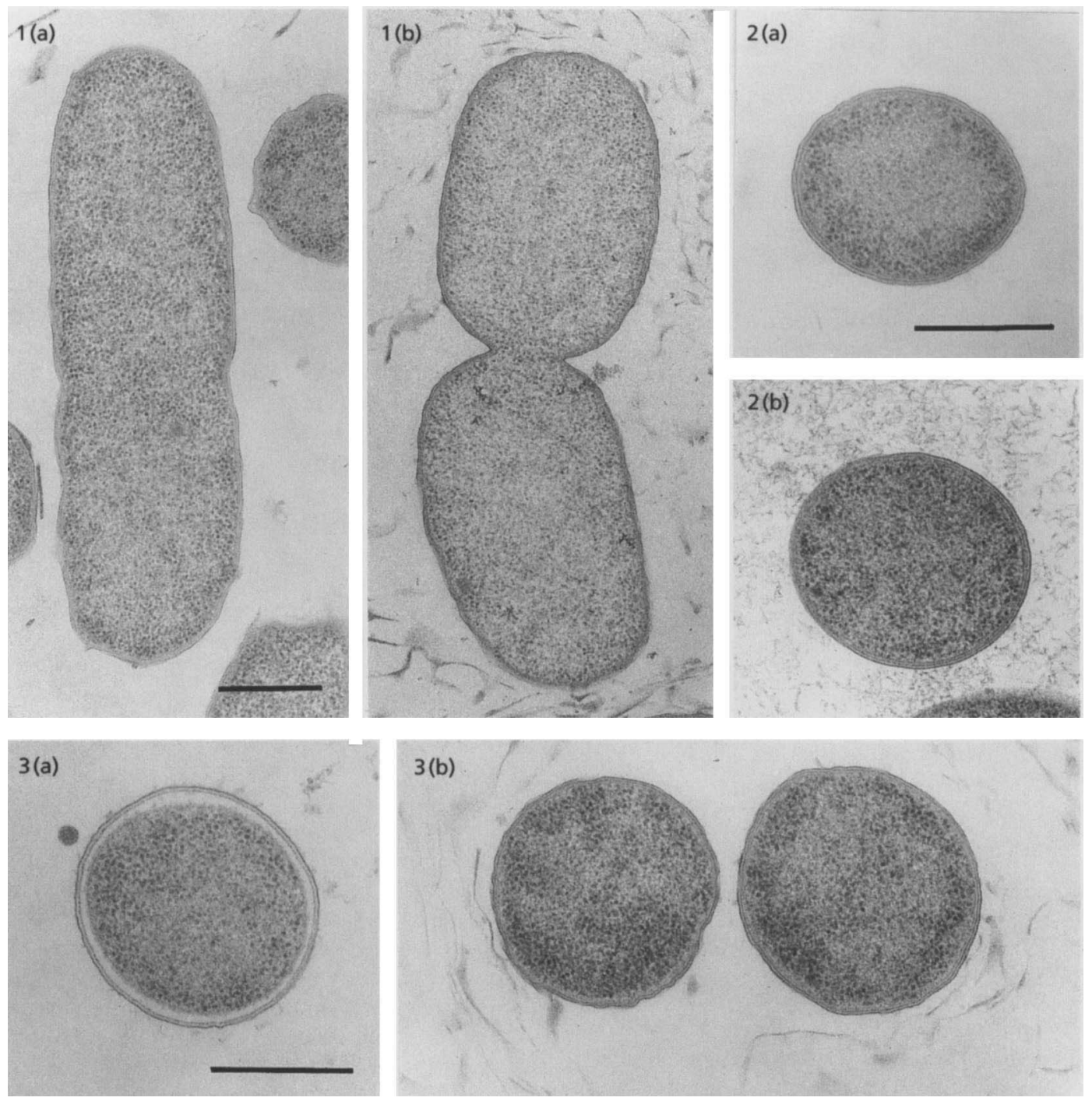

\begin{abstract}
Fig. 1. Longitudinal-sections of cryofixed freeze-substituted E. coli strains CH105Tc (Ipp $\left.{ }^{+}\right)(a)$ and Ch104Tc (Ipp) (b). Both cells are starting to constrict. Examination of many cells showed that the absence of lipoprotein caused no qualitative difference in the appearance of the wall layers. Bar, $0.5 \mu \mathrm{m}$.

Fig. 2. Cross-sections of cryofixed freeze-substituted E. coli strains CH105Tc (Ipp ${ }^{+}$) (a) and Ch104Tc (Ipp) (b). The wall thickness averaged over many sections is 23.7 and $21.9 \mathrm{~nm}$, respectively. Bar, $0.5 \mu \mathrm{m}$.

Fig. 3. Rare morphologies observed in cross-sections of cryofixed freeze-substituted $E$. coli strains. (a) $\mathrm{CH}_{105 T c}\left(/ p p^{+}\right)$ showing very rare unstimulated plasmolysis; this type of periplasmic space is called laminar. (b) Ch104Tc (/pp) showing the wrinkled morphology typical of cells that have been osmotically challenged, but have failed to plasmolyse. In these strains under these conditions such phenotypes occur in $<1$ in 2000 cells. Bar, $0.5 \mu \mathrm{m}$.
\end{abstract}

shows measurements of the entire wall thickness, CM$\mathrm{M}-\mathrm{OM}$, observed in unchallenged non-plasmolysed cells. The $\mathrm{M}-\mathrm{OM}$ distance is smaller in the lipoprotein-deficient strain than in the strain with lipoprotein linking the murein and OM. This difference of $1.9 \mathrm{~nm}$ is statistically significant but marginal in terms of the resolution obtainable even with ultrathin sections of $50-60 \mathrm{~nm}$ used here.

\section{Approximate dimensions of the vesicles and wrinkles}

We presume that the circular sections seen in our studies in this series are spherical bodies and not tubular ones. In certain cases, this is known to be the case because serial section data was obtained, but a more general argument is that we viewed so many of them that if they were tubules or even ellipses that would have occasionally been observed in longitudinal-section, but upon examination of hundreds of such objects it was found that they were always circular or nearly circular. The mean measurements of the diameters of vesicles of the typical small endocytotic vesicles taken from Figs 4(a) and 5(a) were $57 \pm 4$ and $54.8 \pm 2 \mathrm{~nm}$, respectively (values are \pm SEM of $5-7$ measurements). Because the vesicles had dimensions similar to the thickness of the sections, these measurements are rough because only occasionally has the 

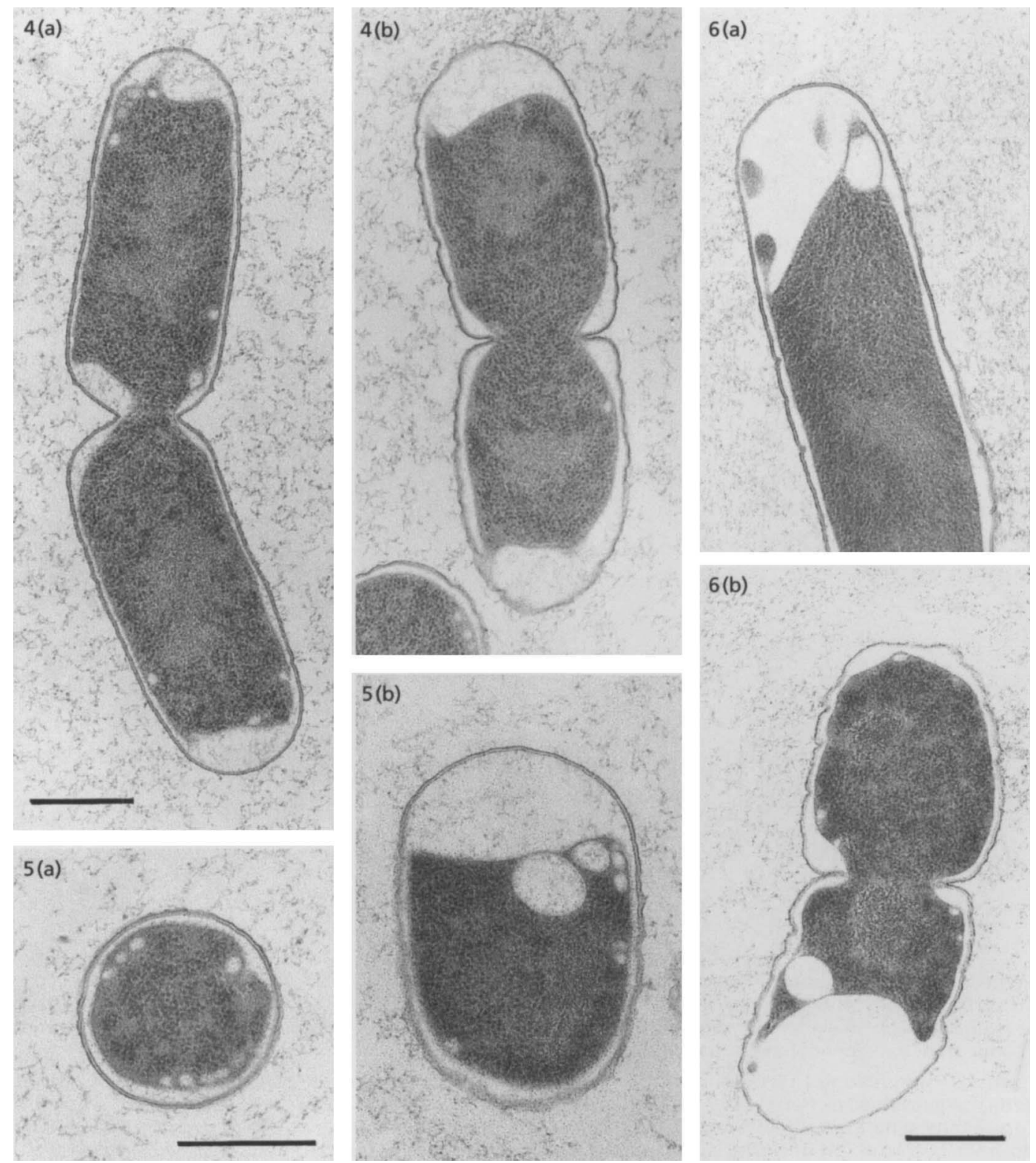

Fig. 4. Osmotically challenged cultures. Longitudinal-sections of cryofixed freeze-substituted $E$. coli strains CH105Tc (lpp ${ }^{+}$) (a) and Ch104Tc (lpp) (b) are shown. For both strains, note the polar and laminar plasmolysis spaces and the spaces at the constriction sites. Note especially the presence of vesicles of a range of sizes. Bar, $0.5 \mu \mathrm{m}$.

Fig. 5. Cross-sections of osmotically challenged cultures. Cryofixed freeze-substituted E. coli strains: (a) CH105TC (/pp ${ }^{+}$). Note the laminar plasmolysis spaces and the vesicles just under the CM. (b) Ch104Tc (Ipp). The occurrence of plasmolysis in this strain is about as common as in the $/ p p^{+}$strains. Unplasmolysed wrinkled cell or regions of cell, such as shown in Fig. 7 (b), were also frequently observed. Bar, $0.5 \mu \mathrm{m}$.

Fig. 6. Interesting rare morphologies of osmotically challenged cultures. Longitudinal-sections of cryofixed freezesubstituted $E$. coli strains. (a) $\mathrm{CH} 105 \mathrm{Tc}\left(/ \mathrm{pp}^{+}\right)$. This cell shows a very large endocytotic vesicle. Note the dark region that may be contained in an outpouching of the $\mathrm{CM}$ or it may be an 'exocytotic vesicle'. In either case it reduces the $\mathrm{CM}$ surrounding the main mass of cytoplasm. (b) Ch104Tc (Ipp). Note the large endocytotic vesicle, the polar spaces, and that the $O M$ is less wrinkled above regions where plasmolysis has taken place. Bar, $0.5 \mu \mathrm{m}$.

sectioning knife cut the top and bottom and left only the middle of the vesicles in view. However, the membranebound character of the vesicle was observed in a number of cell sections. The average wavelength of the wrinkled wall layers at the top of Fig. 7(b) was $103 \pm 8 \mathrm{~nm}$. Only wrinkles that were not associated with vesicles nor any evident plasmolysis spaces were measured and only wrinkled walls, typical in appearance, were chosen for measurement of the peak-to-peak distance of the waves. 

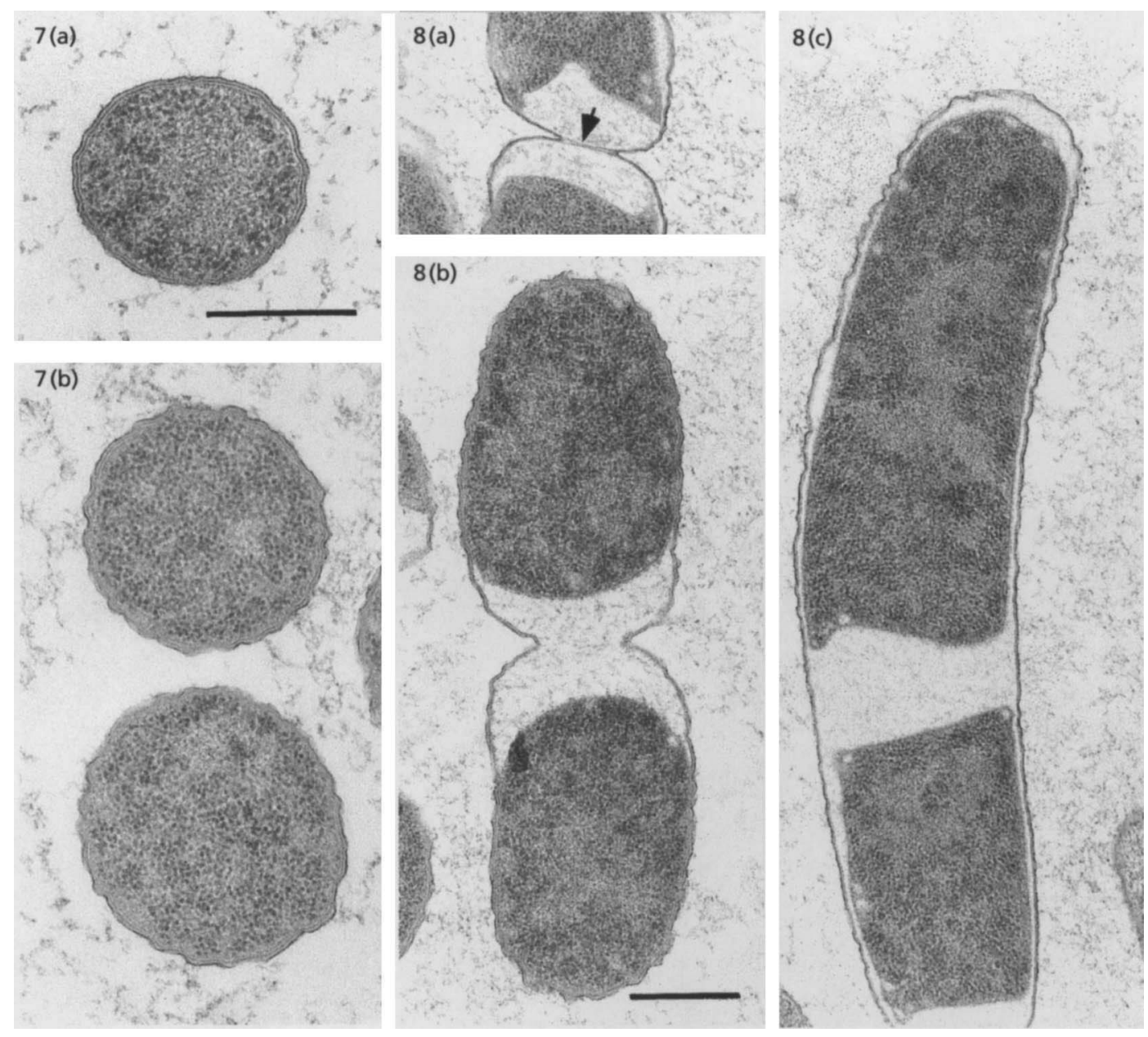

Fig. 7. Wrinkled cells in osmotically challenged cultures that shrank and wrinkled, but did not plasmolyse. Cross-sections of cryofixed freeze-substituted E. coli strains CH105TC (Ipp $\left.{ }^{+}\right)(a)$ and Ch104Tc (Ipp) (b). Note that only the wrinkled structure is present and there are no vesicles. Cross-sections with plasmolysis spaces do occur in the Ipp strains, but the wrinkled appearance is more common than with the Ipp ${ }^{+}$strains. Bar, $0.5 \mu \mathrm{m}$.

Fig. 8. Unusual morphologies observed with the lipoprotein-deficient strain, E. coli strain Ch104Tc (Ipp), osmotically challenged. Longitudinal-sections of cryofixed freeze-substituted preparations are shown. (a) Evidence for the appearance of the separated three layers of the wall, i.e. CM, M and OM. The arrowhead points to peptidoglycan layer separated from both the CM and OM layers. (b) Cell with a complete central plasmolysis site and no evidence of polar spaces. (c) Cell with a plasmolysis space extending all the way through the cell with no evidence of a constriction site. Bar, $0.5 \mu \mathrm{m}$.

\section{Comparison of plasmolysis and shrinking in cells with and without lipoprotein}

Wrinkling, unresolved by plasmolysis, was more common with the lipoprotein-deficient strain than the wild-type. This is a counter intuitive result, but is consistent with EM studies with stronger up-shocks (Koch, 1995; unpublished). It is also consistent with much more numerous unpublished observations made with the light microscope with a wide range of osmotica concentration. With more severe up-shock, the cells are largely collapsed as shown by EM and in the phase microscope such cells appear phase dark. At lower concentrations, individual plasmolysis spaces can be seen. For the present paper, the significance of these data is that they show a weaker up- shock sufficient to cause generalized collapse of the cytoplasm in the lipoprotein-deficient strains so that the entire cell was essentially plasmolysed and the cytoplasm appeared phase dark.

\section{Speed of plasmolysis}

We minimized the time between osmotic up-shock and cryofixation samples in all cases. Even when only one grid was made after up-shock and the time was reduced to $45 \mathrm{~s}$, however, plasmolysis appeared to be no different than when a longer time elapsed before cryofixation as in Figs 3-7. With observation in the phase microscope, plasmolysis appeared to be essentially complete within $15 \mathrm{~s}$ after an exponentially growing culture was mixed on 
Table 1. Mean thicknesses of wall components

Values are \pm SEM of dimensions of individual cells. The number in parentheses is the number of the cells studied, and each one was measured at 4-11 sites on the wall.

\begin{tabular}{|lcc|}
\hline & $\begin{array}{c}\text { CH105Tc } \\
\left(l p p^{+}\right) \mathbf{n m}\end{array}$ & $\begin{array}{c}\text { CH104Tc } \\
(l p p) \text { nm }\end{array}$ \\
\hline Plasmolysed* & & \\
CM & $6 \cdot 8 \pm 0 \cdot 7(7)$ & $6 \cdot 9 \pm 0 \cdot 2(12)$ \\
M-OM & $16 \cdot 9 \pm 0 \cdot 7(12)$ & $15 \cdot 0 \pm 0 \cdot 3(18)$ \\
$\quad$ Total & $23 \cdot 7 \pm 1 \cdot 4$ & $21 \cdot 9 \pm 0 \cdot 4$ \\
Non-plasmolysed† & & \\
CM-M-OM & $21 \cdot 9 \pm 0 \cdot 1(8)$ & $19 \cdot 3 \pm 0 \cdot 6(5)$ \\
Diameter of OM-OM & & \\
cross-sections & & \\
$\quad$ Wrinkled, sucrose treated & $738 \pm 18(12)$ & $862 \pm 23(11)$ \\
$\quad$ Non-sucrose treated & $806 \pm 13(9)$ & $862 \pm 22(14)$ \\
\hline
\end{tabular}

* Plasmolysed cells have been treated with a final concentration of $16 \%$ sucrose and then immediately processed.

† Non-plasmolysed cells that had not been challenged and were in the exponential growth phase when the samples were taken for EM.

the slide with the osmotica. Thus, shrinking, collapse of the cytoplasm and plasmolysis are all so fast that neither technique reveals intermediary changes.

\section{DISCUSSION}

\section{No plasmolysis in non-osmotically challenged cells}

With the technique used of rapid freezing and solvent substitution in the cold (Beveridge \& Graham, 1991; Graham \& Beveridge, 1990a, b; Graham et al., 1991; Hobot et al., 1984; Kellenberger, 1990), we always observed wall images that had parallel sets of lines that showed that the CM, the murein layer, and the OM were always closely and tightly applied to each other and formed a smooth and straight covering of the entire cell (Figs 1 and 2). An especially important observation was that there were almost no observable periplasmic spaces resembling the plasmolysis spaces produced with osmotic challenge. Only very rarely ( $<1$ in 2000 cells) were small and very thin lamellar spaces seen in the sidewall regions and none were seen in the polar regions.

\section{Necessity of wrinkle formation immediately after osmotic challenge}

When a cell is suddenly exposed to an osmotic shock, water rushes out of the cell to equalize the water activity inside and outside. This happens within $0.1 \mathrm{~s}$ (Alemohammad \& Knowles, 1974; Koch, 1984). Because a smaller volume must be contained within the $\mathrm{CM}$, the CM must wrinkle since it cannot contract because phospholipid membranes are not able to shrink more than 2-5\% (Kell \& Glaser, 1993; see Koch, 1995). The physical properties of the phospholipid membranes are certainly highly important to the process of plasmolysis; bilayers are in essence two-dimensional incompressible fluids (see reviews of the physical properties of membrane bilayers in Henis, 1993; Lichtenberg, 1993; Tanford, 1980). The elastic properties of the murein layers are different (Koch \& Woeste, 1992); the murein layer of $E$. coli is capable of elastic expansion/contraction of over a fourfold range in area. It is likely that in most regions of most of the cells in the present study the entire wall envelope became corrugated upon osmotic challenge, as shown in Fig. 7(a,b). We hypothesize that under the conditions of the present work, the CM comes loose from the rest of the envelope in various regions resulting in the formation of plasmolysis spaces. Although the initial dislocation may happen at random (see Koch, 1995, and his analysis of the work of Olijhoek et al., 1982), usually the finally locations are as shown in Figs 4, 5 and 6. The initially wrinkled envelope could have its $M$ and $O M$ partially relaxed and straightened out to some degree as in Figs 4(a), 5(a) and 6(a) or remain partially wrinkled as in Figs 4(b), 5(b) and 6(b).

\section{Small size of the periplasmic space in unchallenged cells}

In physiological terms, the periplasmic space is the volume of water in which probe molecules can mix between the outer and the inner membranes. Using probes, such as tracer sucrose or taurine, this volume is the extra volume in the culture that these molecules can occupy that larger molecules cannot. This value is expressed relative to the cellular volume that $\mathrm{H}_{2} \mathrm{O}$ can occupy and that larger molecules, such as inulin, cannot. In the recent discussions in the literature (Ferguson, 1990, 1992; Graham \& Beveridge, 1990a, b; Graham et al., 1991; Cayley et al., 1991; Wielink \& Duine, 1990), the volume of the periplasmic space has been variously estimated as covering a range from 5 to $70 \%$ of the cell volume.

From the experiments reported in Table 1, the total volume of space in the periplasm was calculated as a percent of the total volume of the cell assuming that the cell shape could be adequately represented as a cylinder with hemispherical poles. From the thicknesses of the wall components, the diameter of cross-section, and the average length, the uncorrected periplasmic space was calculated to be $11.8 \%$ for the Ch105 $l p p^{+}$and $9.8 \%$ for the Ch104 lpp cells. With various types of corrections (itemized by Koch, 1995), the value decreases to about $7 \%$, much less than some values reported with other ultrastructural methods and less than any of the isotope dilution techniques. The significance of these differences is discussed by Koch (1995).

\section{Kinetics of plasmolysis}

With the EM or with the phase contrast microscope, our fastest technique is far too slow to follow the kinetics of the process and to document the sequence of events. The stopflow measurements of Koch (1984) and of Knowles' laboratory (Knowles, 1971; Alemohammad \& Knowles, 
1974) are fast enough to show that the osmotic responses are very rapid (ms), but unfortunately they do not distinguish between shrinkage with concomitant wrinkling of all layers and the separation of the $\mathrm{CM}$ from the $\mathrm{M}-\mathrm{OM}$ layer which remains nearly stationary. We prepared cryofrozen samples as quickly as possible, but found that the appearance of cells at $45 \mathrm{~s}$ after osmotic shock was no different than with the usual procedure. With phase microscopic studies we could look at the cells on a shorter time scale (but not, however, less than $15 \mathrm{~s}$ ). Therefore, both techniques are much too slow to study the primary event, but they do limit the time for possible secondary rearrangements.

\section{Formation of vesicles}

Assuming that wrinkling precedes plasmolysis and the concomitant formation of endocytotic vesicles, the dimensions of the wave in wall of an osmotically challenged cell may change with time after the challenge; this is important because the cells of Figs 4(a) and 5(a) were cryofixed as fast as possible, but this was several minutes after the osmotic challenge. In spite of these uncertainties, if vesicles are formed by the successive low points in the waves fusing together, then $\pi$ divided into the period of a wave should give rise to the resultant vesicle's diameter; their dimensions are not inconsistent with this hypothesis of wave-to-vesicle conversion.

The observation of endocytotic vesicles formation is wellknown in animal cells as part of the phenomena of phagocytosis and pinocytosis, but it has also been observed in wall-less plant cells (Kell \& Glaser, 1993). In fact, even for bacteria our findings are not unique; vesicles were evident in previous publications by others (Anba et al., 1984; Bayer, 1991; Hobot et al., 1984; Kellenberger, 1990; MacAlister et al., 1987) in electron micrographs of plasmolysed cells. E. Kellenberger (University of Lausanne, Switzerland; personal communication) has also observed such vesicles under different conditions. However, none of these authors remarked on their existence and/or their possible (or necessary) roles in plasmolysis. The vesicles are abundant in Figs 4-6, and their formation allows a diminution of the CM covering the cytoplasm. The geometric situation in which vesicle formation is necessary for plasmolysis space formation is when there is no simple shape that the CM can adopt that conserves the area such as the poles or the constricting regions of the cell. Under more severe up-shock than used here (Koch, 1995; Schwarz \& Koch, unpublished), the highly shrunken cytoplasm may maintain a rough appearance of its CM covering, or a non-cylindrical crosssection (called Scheie structures), or with tubular structures emanating from the $\mathrm{CM}$ and nearly reaching the $\mathrm{M}-\mathrm{OM}$ layer (Bayer adhesions or bridges).

\section{Role of the lipoprotein}

The lipoprotein (for a recent review see Braun \& Wu, 1994) forms multiple strong hydrophobic bonds with the inner leaflet of the OM and becomes covalently attached to the $\mathrm{M}$ layer. Because the attachment to the murein is delayed (Hiemstra, 1987; Hiemstra et al., 1987), one can account for the preference for polar spaces to form at the new pole (Mulder \& Woldringh, 1993), but surprisingly we observed only minor changes in comparing two pairs of isogenic strains. These differences were also demonstrated by the dependence on the severity of the up-shock; larger concentrations of osmotic agents were required to plasmolyse the $l p p$ than the isogenic wild-type strain.

\section{Development and geometry of plasmolysis spaces without the necessity of vesicle formation or disposition of CM bilayer in other ways}

There are two locations in the cell where plasmolysis spaces can develop without requiring the formation of vesicles. These cases are mathematically analysed in Koch (1995). One of these is the formation of polar spaces. This is the simplest case not requiring endocytosis of $\mathrm{CM}$, because the area of the membrane need not change in the inversion of the cell membrane from a convex to a concave form. This argument for the low energy requirement for formation is consistent with the prevalence of polar spaces (Mulder \& Woldringh, 1993).

The other site where formation of plasmolysis spaces with conservation of membrane is the central region where a constriction has developed as the prelude to cell division. Such sites are shown in Figs 4(a, b), 6(a, b) and 8(a,b) and which we observe quite frequently. At such constriction sites, the wall has already grown inward but division is not yet complete. The theoretical analysis of shapes of plasmolysis spaces under conditions of constant area is reported in Koch (1995). The absence of requirement for vesicle formation for this type of space is consistent with their frequent observation.

\section{ACKNOWLEDGEMENTS}

The authors wish to thank Tina Romeis for pointing out the importance of the vesicles, Angelika Kraft for pointing out that the two leaflets of the cytoplasmic bilayer could shift relative to each other in developing wrinkles, and to Marcus Templin for destroying a suggestion of the junior author. We wish to thank Professors William Baldwin, Volkmar Braun, Joachim-Volker Höltje, Uli Schwarz, and Conrad Woldringh for useful discussions, and J.-V. Höltje and U. Schwarz for accommodating A.L.K. during a sabbatical at the Max Planck Institute for Developmental Biology in Tübingen. We also wish to thank Henry Wu at the Uniformed Services University in Washington, DC, and to thank Professor Shibuya of Saitama University, Japan, for supplying strains. Special thanks are due to Inge Zimmerman for careful but laborious preparation of the thin sections.

\section{REFERENCES}

Anba, J., Bernadac, A., Pages, J.-M. \& Lazdunski, C. (1984). The periseptal annulus in Escherichia coli. Biol Cell 50, 273-278.

Alemohammad, M. M. \& Knowles, C. J. (1974). Osmotically induced volume and turbidity changes of Escherichia coli due to salt, sucrose, glycerol, with particular reference to the rapid permeation of glycerol into the cell. J Gen Microbiol 82, 125-142. 
Asaai, Y., Katayose, Y., Hikita, C., Ohta, A. \& Shibuya, I. (1989). Suppression of the lethal effect of acidic-phospholipid deficiency by defective formation of the major outer membrane lipoprotein in Escherichia coli. J Bacteriol 171, 6867-6869.

Bayer, M. E. (1991). Zones of membrane adhesion in the cryofixed envelope of Escherichia coli. J Struct Biol 107, 268-280.

Beveridge, T. J. \& Graham, L. L. (1991). Surface layers of bacteria. Microbiol Rev 55, 634-705.

Braun, V. \& Wu, H. C. (1994). Lipoproteins, structure, function, biosynthesis and model for protein export. In Bacterial Cell Wall, pp. 319-341. Edited by J.-M. Ghuysen \& R. Hakenbeck. Amsterdam: Elsevier.

Cayley, S., Lewis, B. A., Guttman, H. J. \& Record, M. T., Jr (1991). Characterization of the cytoplasm of Escherichia coli K-12 as a function of external osmolarity. $J$ Mol Biol 222, 281-300.

Clark, D. J. (1968). The regulation of DNA replication and division cycle in E. coli. Cold Spring Harb Symp Quant Biol 33, 823-838.

Cook, W. R. \& Rothfield, L. I. (1994a). Early stages in development of the Eschericbia coli cell-division site. Mol Microbiol 14, 485-495.

Cook, W. R. \& Rothfield, L. I. (1994b). Development of the cell division site in FtsA ${ }^{-}$filaments. Mol Microbiol 14, 497-503.

Cook, W. R., Kepes, F., Joseleau-Petit, D., MacAlister, T. J. \& Rothfield, L. I. (1987). Proposed mechanism for the generation and localization of new division sites during the division cycle of Escherichia coli. Proc Natl Acad Sci US A 84, 7144-7148.

Cook, W. R., De Boer, P. A. J. \& Rothfield, L. I. (1989). Differentiation of the bacterial cell division site. Int Rev Cytol 118, 1-31.

Cota-Robles, E. H. (1963). Electron microscopy of plasmolysis in Escherichia coli. J Bacteriol 85, 499-503.

Ferguson, S. J. (1990). Periplasm underestimated. Trends Biochem Sci 15, 327-329.

Ferguson, S. J. (1992). The periplasm. In Prokaryotic Structure and Function: a New Perspective, pp. 311-339. Society for General Microbiology Symposium, vol. 47. Edited by S. Mohan, C. Dow \& J. A. Cole. Cambridge: Cambridge University Press.

Fischer, A. (1891). Die plasmolyse der bacteria. Ber Kgl Sach Ges Wissensch Math Phys CL 43, 53-74.

Graham, L. L. \& Beveridge, T. J. (1990a). Evaluation of freezesubstituted and conventional embedding protocols for routine electron microscopic processing of eubacteria. J Bacteriol 172, 2141-2149.

Graham, L. L. \& Beveridge, T. J. (1990b). Effect of chemical fixatives on accurate preservation of Eschericbia coli and Bacillus subtilis structures in cells prepared by freeze-substitution. J Bacteriol 172, 2150-2159.

Graham, L. L., Beveridge, T. J. \& Nanninga, N. (1991). Periplasmic space and the concept of the periplasm. Trends Biochem Sci 16, 328-329.

Heilbrunn, L. V. (1952). An Outline of General Physiology, 3rd edn, pp. 121-135. W. B. Saunders: Philadelphia.

Henis, Y. I. (1993). Lateral and rotational diffusion in biological membranes. In Biomembranes: Physical Aspects, pp. 279-289. Edited by M. Shinitzky. Weinheim: VCH.

Hiemstra, H. (1987). Topology of lipoprotein assembly in the cell wall of Escherichia coli. PhD thesis, University of Groningen.

Hiemstra, H., Nanninga, N., Woldringh, C. L., Inouye, M. \& Witholt, B. (1987). Distribution of newly synthesized lipoprotein over the outer membrane and the peptidoglycan sacculus on an Escherichia coli lac-lpp strain. J Bacteriol 169, 5434-5444.

Hirota, Y., Suzuki, H., Nishimura, Y. \& Yasuda, S. (1977). On the process of cellular division in Escherichia coli. Proc Natl Acad Sci US A 74, 1417-1420.

Hobot, J. A., Carlemalm, E., Villiger, W. \& Kellenberger, E. (1984). Periplasmic gel: a new concept resulting from the reinvestigation of the bacterial envelope ultrastructure by new methods. $J$ Bacteriol $162,143-152$.

Kell, A. \& Glaser, R. W. (1993). On the mechanical and dynamic properties of plant cell membranes: their role in growth, direct gene transfer and protoplast fusion. J Theor Biol 160, 41-62.

Kellenberger, E. (1990). The 'Bayer bridges' confronted with results from improved electron microscopy. Mol Microbiol 5, 19-22.

Kennedy, E. P. (1982). Osmotic regulation and the biosynthesis of membrane-derived-oligosaccharides in Eschericbia coli. Proc Natl Acad Sci US A 78, 1092-1095.

Knowles, C. J. (1971). Salt induced changes of turbidity and volume of E. coli. Nat New Biol 229, 154-155.

Koch, A. L. (1961). Some calculations on the turbidity of mitochondria and bacteria. Biocbim Biophys Acta 51, 429-441.

Koch, A. L. (1984). Shrinkage of growing Escherichia coli cells through osmotic challenge. J Bacteriol 159, 914-924.

Koch, A. L. (1995). The geometry and osmotic relations of plasmolysis spaces in bacteria and the role of endocytosis, tubular structures, and Scheie structures in their formation. J Theor Biol 176 471-492.

Koch, A. L. \& Woeste, S. W. (1992). The elasticity of the sacculus of Escbericbia coli. J Bacteriol 174, 4811-4819.

Lichtenberg, D. (1993). Micelles and liposomes. In Biomembranes: Physical Aspects, pp. 63-95. Edited by M. Shinitzky. Weinheim: $\mathrm{VCH}$.

MacAlister, I. J., Cook, W. R., Weigand, R. \& Rothfield, L. I. (1987). Membrane-murein attachment at the leading edge of the division septum: a second membrane-murein structure associated with the morphogenesis of the gram-negative division septum. $J$ Bacteriol 169, 3945-3951.

MacAlister, T. J., MacDonald, B. \& Rothfield, L. I. (1983). The periseptal annulus: an organelle associated with cell division in Gram-negative bacteria. Proc Natl Acad Sci US A 80, 1372-1376.

Miller, J. H. (1972). Experiments in Molecular Genetics. Cold Spring Harbor, NY: Cold Spring Harbor Laboratory.

Mulder, E. \& Woldringh, C. L. (1993). Plasmolysis bays in Escherichia coli: are they related to development and positioning of division sites? J Bacteriol 175, 2241-2247.

Nakamura, K., Masui, Y. \& Inouye, M. (1982). Use of a lac promoter-operator fragment as a transcriptional control switch for the expression of constitutive lpp gene in Escherichia coli. J Mol Appl Gen 1, 2789-2799.

Nobel, P. S. (1983). Biophysical Plant Physiology and Ecology. San Francisco: W. H. Freeman.

Olijhoek, A. J. M., van Eden, C. G., Trueba, F. J., Pas, E. \& Nanninga, N. (1982). Plasmolysis during the division cycle of Eschericbia coli. J Bacteriol 152, 479-484.

Rothfield, L. I., Cook, W. R. \& De Boer, P. A. (1991). Biogenesis of the Escberichia coli cell division system. Cold Spring Harbor Symp Quant Biol 56, 752-756.

Schwarz, H., Hohenberg, H. \& Humbel, B. M. (1993). Freezesubstitution in virus research: a preview. In Imunogold Electron Microscopy in Virus Diagnosis and Research, pp. 349- 376. Edited by A. D. Hyatt \& B. T. Eaton. Boca Raton, FL: CRC Press.

Sonntag, I., Schwarz, H., Hirota, Y. \& Henning, U. (1978). Cell envelope and shape of Escherichia coli: multiple mutants missing the 
outer membrane lipoprotein and other major outer membrane proteins. J Bacteriol 136, 280-285.

Stock, J. B., Rauch, B. \& Roseman, S. (1977). Periplasmic space in Salmonella typhimurium and Escherichia coli. J Mol Biol 252, 7850-7861. Suzuki, H., Nishimura, Y., Yasuda, S., Yamada, M. \& Hirota, Y. (1978). Murein-lipoprotein of Escherichia coli: a protein involved in the stabilization of the bacterial cell envelope. Mol \& Gen Genet 167, 1-9.

Tanford, C. (1980). The Hydrophobic Effect: Formation of Micelles and Biological Membranes, 2nd edn. New York: Wiley.

de Vries, H. (1877). Untersucbungen ueber die mechanischen Ursacben der Zellstreckung. Leipzig: W. Engelmann.

Wielink, J. E. \& Duine, J. A. (1990). How big is the periplasmic space? Trends Biochem Sci 15, 136-137.
Woldringh, C. L. (1994). Significance of plasmolysis spaces as markers for periseptal annuli and adhesion sites. Mol Microbiol 14, 597-607.

Zhang, W.-Y. \& Wu, H. C. (1992). Alterations of the carboxylterminal amino acid residues of Eschericbia coli lipoprotein affect the formation of murein-bound lipoprotein. $J$ Biol Chem 267, 19560-19564.

Zhang, W.-Y., Inouye, M. \& Wu, H. C. (1992). Neither lipid modification nor processing of prolipoprotein is essential for the formation of murein-bound lipoprotein in Escherichia coli. $J$ Biol Chem 267, 19631-19635.

Received 10 May 1995; accepted 21 August 1995. 